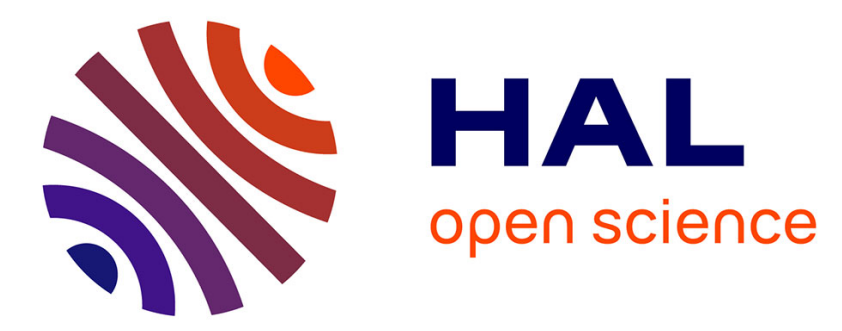

\title{
Ecological niche overlap in sister species: how do oil-collecting bees Macropis europaea and Macropis fulvipes (Hymenoptera: Melittidae) avoid hybridization and competition?
}

Lucas Bassin, Nadir Alvarez, Loïc Pellissier, Yann Triponez

\section{To cite this version:}

Lucas Bassin, Nadir Alvarez, Loïc Pellissier, Yann Triponez. Ecological niche overlap in sister species: how do oil-collecting bees Macropis europaea and Macropis fulvipes (Hymenoptera: Melittidae) avoid hybridization and competition?. Apidologie, 2011, 42 (5), pp.579-595. 10.1007/s13592-011-0067-z . hal-01003603

\section{HAL Id: hal-01003603 \\ https://hal.science/hal-01003603}

Submitted on 1 Jan 2011

HAL is a multi-disciplinary open access archive for the deposit and dissemination of scientific research documents, whether they are published or not. The documents may come from teaching and research institutions in France or abroad, or from public or private research centers.
L'archive ouverte pluridisciplinaire HAL, est destinée au dépôt et à la diffusion de documents scientifiques de niveau recherche, publiés ou non, émanant des établissements d'enseignement et de recherche français ou étrangers, des laboratoires publics ou privés. 


\title{
Ecological niche overlap in sister species: how do oil-collecting bees Macropis europaea and Macropis fulvipes (Hymenoptera: Melittidae) avoid hybridization and competition?
}

\author{
Lucas Bassin ${ }^{1}$, Nadir Alvarez ${ }^{2}$, Loïc PellissieR ${ }^{2}$, Yann Triponez ${ }^{1}$ \\ ${ }^{1}$ Laboratoire d'Entomologie Evolutive, Institut de Biologie, Université de Neuchâtel, Rue Emile-Argand 11, cp 158, \\ CH-2009 Neuchâtel, Switzerland \\ ${ }^{2}$ Département d'Ecologie et Evolution, Université de Lausanne, Lausanne, Switzerland
}

Received 21 September 2010 - Revised 15 December 2010 - Accepted 17 December 2010

\begin{abstract}
Oil-collecting bees are found worldwide and always in association with particular oil-producing flowers. In the Western Palearctic, three oil-collecting bee species within the genus Macropis (Hymenoptera, Melittidae) interact in a tight pollination mutualism with species of the only European oil-producing plant genus Lysimachia L. (Myrsinaceae). Two of these oil-collecting bees (Macropis europaea and Macropis fulvipes) show overlapping geographic distributions, comparable morphologies, and similar ecological characteristics (e.g., habitat type, floral preferences). In view of these similarities, we presume that hybridization should occur between the two species unless potential variation among the species' ecological niches prevents it, simultaneously decreasing competition for resources. Using modern genetic analyses and ecological niche modeling on a large bee sampling throughout Europe, we discuss new perspectives on the ecology and evolutionary history of this mutualism.
\end{abstract}

\section{Macropis / mutualism / Lysimachia / ecological niche / hybridization}

\section{INTRODUCTION}

Mutualisms between insects and plants are widely recognized as indispensable components in ecosystems functioning (Bronstein et al. 2006). Among the most fascinating plant-insect mutualisms, many nursery pollination systems have been documented, notably in the fig/fig wasps and the yucca/yucca moths interactions (e.g.,

Electronic supplementary material The online version of this article (doi:10.1007/s13592-011-0067-z) contains supplementary material, which is available to authorized users.

Corresponding author: Y. Triponez, yann.triponez@bluewin.ch Manuscript editor: Stan Schneider
Pellmyr 2003; Cook and Rasplus 2003; Machado et al. 2005). In contrast, specific pollination systems involving oil-producing plants and oilcollecting bees have been much less studied (Vogel 1988). In such systems, oil-offering flowers, found worldwide in 11 different plant families (Renner and Schaefer 2010), are pollinated by specifically adapted oil-collecting bees distributed in a few genera within Melittidae and Apidae families. Such bees use oil combined with pollen as larval food, for water-resistant lining of larval cells, or both (Renner and Schaefer 2010). Oil-collecting bees have developed special branched hairs on the legs or abdomen to facilitate oil transportation (Rasmussen and Olesen 2000), an adaptation observed on the 53-Mya-old fossil species Palaeomacropis 
eocenicus (Michez et al. 2007), which attests to the ancient nature of coevolutionary processes within this interaction.

In temperate habitats, only a few species have developed such adaptations. Among them are species within the genus Macropis Panzer 1809 (Hymenoptera, Melittidae), one of the 14 genera included in Melittidae (Michener 2000). The 16 species of the genus are subdivided into three subgenera (Macropis s. str., Paramacropis Popov and Guiglia 1936, and Sinomacropis Michener 1981), spanning the Holarctic (Michez and Patiny 2005). All Macropis taxa visit, collect oil, and pollinate the yellow flowers of Lysimachia species (Myrsinaceae; Vogel 1976). Evidence of floral oil was found in at least 75 among the 191 species of Lysimachia (Vogel 1986, 1988; Hao et al. 2004). Here, the oil is produced by elaiophores (oil-secreting trichomes) located at the basal part of petals and anther filaments (Simpson et al. 1983). These plants are native either of temperate Eurasia (subgenus Lysimachia s. str.) or northern America (subgenus Seleucia; Hao et al. 2004). As in the great majority of mutualistic interactions, strict one-to-one relationships between oil-collecting bees and Lysimachia species do not represent the general rule; hence, each plant species is generally visited by more than one species of oilcollecting bees, depending on localization and period of flowering (Cane et al. 1983; Simpson et al. 1983; Pekkarinen et al. 2003; Celary 2004).

Three species of Macropis are found in the western Palearctic ecozone: Macropis europaea Warncke 1973, Macropis frivaldszkyi Mocsary 1878, and Macropis fulvipes Fabricius 1805 (Michez and Patiny 2005). All three species can be found together in sympatric populations (Celary 2004; Pekkarinen et al. 2003; Bassin and Triponez, personal observation). Among them, M. frivaldszkyi (for which very little documentation is currently available relative to its ecological characteristics) shows the narrowest distribution (Balkans, Anatolia, Syria). In contrast, M. europaea and M. fulvipes are widely distributed and hold rather similar ranges across Europe, although the former species is more restricted eastwards (in Russia) and even absent from Anatolia or Caucasus, and the latter does not reach the Scandinavian Peninsula (i.e., Sweden and Norway) and the British Islands (Michez and Patiny 2005). These two species display a high level of similarity in their morphology, behavior, habitat, and floral preferences. For instance, a comparative study established in southern Poland (Celary 2004) showed that all features concerning the nest's architecture and the larval stages differ almost only in size (always slightly bigger for $M$. fulvipes). The most obvious difference between the two species seems to stand in their respective phenologies, with a flight period delayed of about 10 days to 3 weeks (independently observed in different regions of Europe; Westrich 1990; Michez 2002; Pekkarinen et al. 2003; Celary 2004). Such an offset in flight periods might be meaningful for resource partitioning in sympatric Macropis populations, especially in places where only one Lysimachia species is available (Celary 2004). The floral preferences of bees (reviewed by Michez and Patiny 2005) reveal that Lysimachia vulgaris seems to be the main resource of oil for both $M$. europaea and $M$. fulvipes. It might even be the only one for the strictly monolectic $M$. europaea. M. fulvipes was additionally observed on Lysimachia nummularia (sometimes presumed as its preferred plant species [Westrich 1990; Michez 2002; Pekkarinen et al. 2003]) and on Lysimachia punctata (especially in its native area in Anatolia and Caucasus; Triponez, personal observation).

In the current study, our aim was to address whether or not $M$. europaea and M. fulvipes are able to efficiently avoid excessive competition and counter-selected hybridization, despite their similar ecologies and frequent syntopy on $L$. vulgaris. Based on a large-scale sampling all over Europe, we compared the bees' ecological niches and analyzed the sampled specimens using both gene sequencing and Amplified Fragment Length Polymorphism (AFLP) genotyping in order to answer the following questions. (1) How distantly related are these two species from a genetic point of view? (2) Can hybrids between $M$. europaea and M. fulvipes 
be detected, and how frequently? (3) On which ecological properties do the ecological niches of the two species differ? (4) How do these potential ecological differences affect their coexistence and allow them to avoid competition for resources and hybridization? So far, no study has provided objective data to answer these questions.

\section{MATERIAL AND METHODS}

\subsection{Field work}

As a first step to identify potential populations of Macropis, we used international and national freely accessible databases to locate sites of $L$. vulgaris, $L$. nummularia, and L. punctata (in its native area) across Europe. The sampling and the observations of Macropis in Europe were performed mainly during summers 2006 to 2008, each year between June and August depending on the region. Because of the tight interaction between the plant and the bee, as soon as a Lysimachia population was found, Macropis females could be catch easily while pollinating the flowers. If active, patrolling males were also collected in flight with an insect net. We aimed at capturing between five and ten bees per population. All insects were conserved in $70 \%$ ethanol. The three Macropis species were determined following Michez and Patiny (2005). A complementary study describing the pollinators of $L$. nummularia was carried out in parallel in June and July 2008 (see Supplementary material).

\subsection{Genetic distance between $M$. europaea and $M$. fulvipes and detection of putative hybrids}

Total genomic DNA was extracted using the DNeasy Blood \& Tissue Kit (Qiagen, Hilden, Germany) from the wing muscles of the bees carefully removed and rinsed, in order to avoid plant DNA contamination via pollen grains stuck to the bees' exoskeleton. To estimate the genetic distance between M. europaea and M. fulvipes, we chose four individuals (from distant origins) for each bee species and sequenced three mtDNA regions classically used for barcoding: (1) 16s ribosomal RNA (16s rRNA, using the primers LR-N-13398 and LR-J-12883 from Simon et al., 1994), (2) partial cytochrome oxidase I (COI, with the primers C1-J-1751 and C1-N-2191 from Simon et al., 1994), and (3) partial cytochrome B $(C y t B$, using primers designed by Belshaw and Quicke 1997). Fragments were amplified using a standard $30 \mu \mathrm{l} \mathrm{PCR}$ mix. The PCR were run in a TGradient thermocycler (Biometra, Goettingen, Germany) using the same program for all mtDNA regions (the detailed composition of PCR mix and conditions of PCR amplification steps are available on request to the last author). The PCR product purification and sequencing was carried out by Macrogen Inc. (Seoul, South Korea). Sequencing was performed using forward primers for all mtDNA regions under BigDye TM terminator cycling conditions, purifying the products using ethanol precipitation and running them into an automated sequencer 3730xl (Applied Biosystems, Foster City, USA). Sequences were manually corrected using the software Chromas Pro 1.34 (Technelysium, Helensvale, Australia). Alignment was carried out for each mitochondrial region using ClustalW Multiple Alignment (Thompson et al. 1997) as implemented in the software BioEdit 7.0.5.3 (Hall 1999), followed by minor manual corrections. Kimura two-parameter genetic distances between species and general statistics were calculated using MEGA 4 (Kumar et al. 2008).

In order to detect potential hybridization among Macropis species, we used Amplified Fragment Length Polymorphism (AFLP) genome fingerprinting. AFLP analyses were performed following the classical method described by Vos et al. (1995), with slight modifications (detailed protocol available upon request to the last author). Reactions were conducted in 96-well plates, in which samples were randomly distributed. We used restriction enzymes EcoRI and MseI for DNA digestion. A primer trial on a small number of samples was conducted using six different primer combinations to identify pairs of selective primers that were reproducible and polymorphic enough. Each individual sample was subsequently fingerprinted with the two primer combinations EcoRI-ACA/MseI-CAA and EcoRI-ACG/MseICAA. Final selective PCR products were analyzed using the GeneScan technology with an automated capillary sequencer (ABI 3730XL, Applied Biosys- 
tems, Foster City, CA; service provided by Macrogen Inc., Seoul, South Korea). Resulting fluorescent AFLP patterns were scored using GeneMapper 3.7 (Applied Biosystems) with some changes in default parameters (maximum bin width $=1 \mathrm{bp}$, light peak smoothing, peak threshold $=200 \mathrm{RFU}$ ). We scored the presence or absence of each AFLP marker in all specimens. The matrices of the two scored primer pairs were concatenated into one single binary matrix where individuals and bands were stored as lines and columns, respectively. Multivariate ordinations using the principal coordinate analysis ( $\mathrm{PCoA}$ ) approach were produced on this distance matrix to investigate genetic relationships among specimens and taxa using the software Ginkgo 1.5.8 (Bouxin 2005). The PCoA relied on the Jaccard similarity coefficient (Jaccard 1908) to avoid grouping terminals on the basis of shared absences.

\subsection{Ecological niche modeling in $M$. europaea and M. fulvipes}

We modeled the current distribution of $M$. europaea and M. fulvipes using seven modeling techniques implemented in the BIOMOD (Thuiller et al. 2009) R package (see detailed protocol provided as Supplementary material). Models were calibrated from presences collected during the field sampling pooled with occurrences from the data collected by Michez and Patiny (2005) and using seven climatic layers from Worldclim (Hijmans et al. 2005). An ensemble forecasting approach (Marmion et al. 2009) was then used to project a central tendency from a combination of the models obtained by the different niche-based modeling techniques into current climate conditions in Europe. Ecological niches of both species were displayed on the same referential, a multi-dimensional scale represented by the two first axes of a principal component analysis (PCA; see detailed method of Broennimann et al. (in press) provided in Supplementary material). We finally used the geographical data recorded during field work to calculate the correlation between the presence of each bee species and both altitude and latitude, and we tested if the two species showed significant differences regarding both factors by performing either a $t$ test or a one-way ANOVA for altitude, or a MannWhitney rank sum test for latitude. All statistical analyses were performed with the program SigmaStat version 2.03 (SPSS Inc., Chicago, USA).

\section{RESULTS}

\subsection{Macropis sampling}

In total, 94 Macropis populations, comprising one or two species, were collected in Europe, Turkey, and Georgia during bees' main period of activity (Table I; Figure 1). Macropis europaea was the most frequently observed, as illustrated by our total sampling of 419 individuals collected in 74 populations between 25 June and 19 August. It was followed by $M$. fulvipes, represented by 195 individuals collected in 34 populations between 25 June and 10 August. Macropis frivaldszkyi was the least frequently sampled, with only eight individuals from three populations restricted to Serbia and Turkey, between 9 July and 12 July. All specimens are deposited at the Department of Ecology and Evolution from the University of Lausanne, Switzerland. Fifty-eight populations comprised only $M$. europaea (in white on Figure 1), 18 only M. fulvipes (in gray), and one single only $M$. frivaldszkyi (in black). Sympatric populations were also found: in 15 sites from Western and central Europe, both $M$. europaea and M. fulvipes were sampled; Macropis frivaldszkyi was observed in sympatry with $M$. europaea in a single location in Serbia (population KRU) and with M. fulvipes in a single location in Turkey (population ERF). Sympatry cannot be excluded in several sites comprised in the western distribution range of M. fulvipes, in which only M. europaea was collected, as ten French and Spanish locations (ASP, BAZ, BOV, CAM, CAP, CAR, CRU, JUG, MAV, and PUE; see Table I) that were visited later than August 10 (i.e., the latest appearance of $M$. fulvipes in our sampling). Although M. fulvipes females seem to be active until late August (Westrich 1990; Celary 2004), an earlier sampling in July would confirm or invalidate its actual absence in these sites. Regarding floral preferences, M. europaea was 


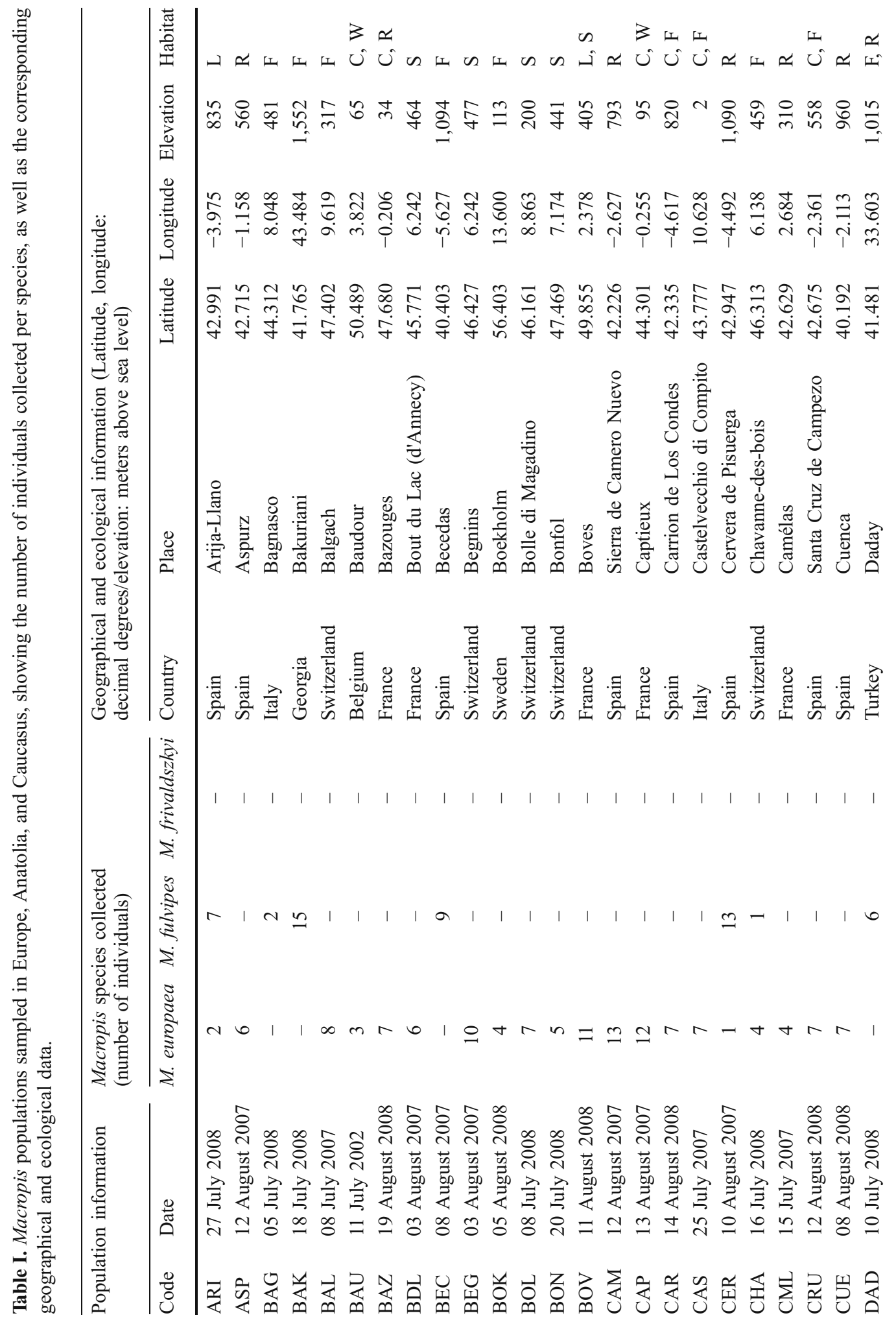




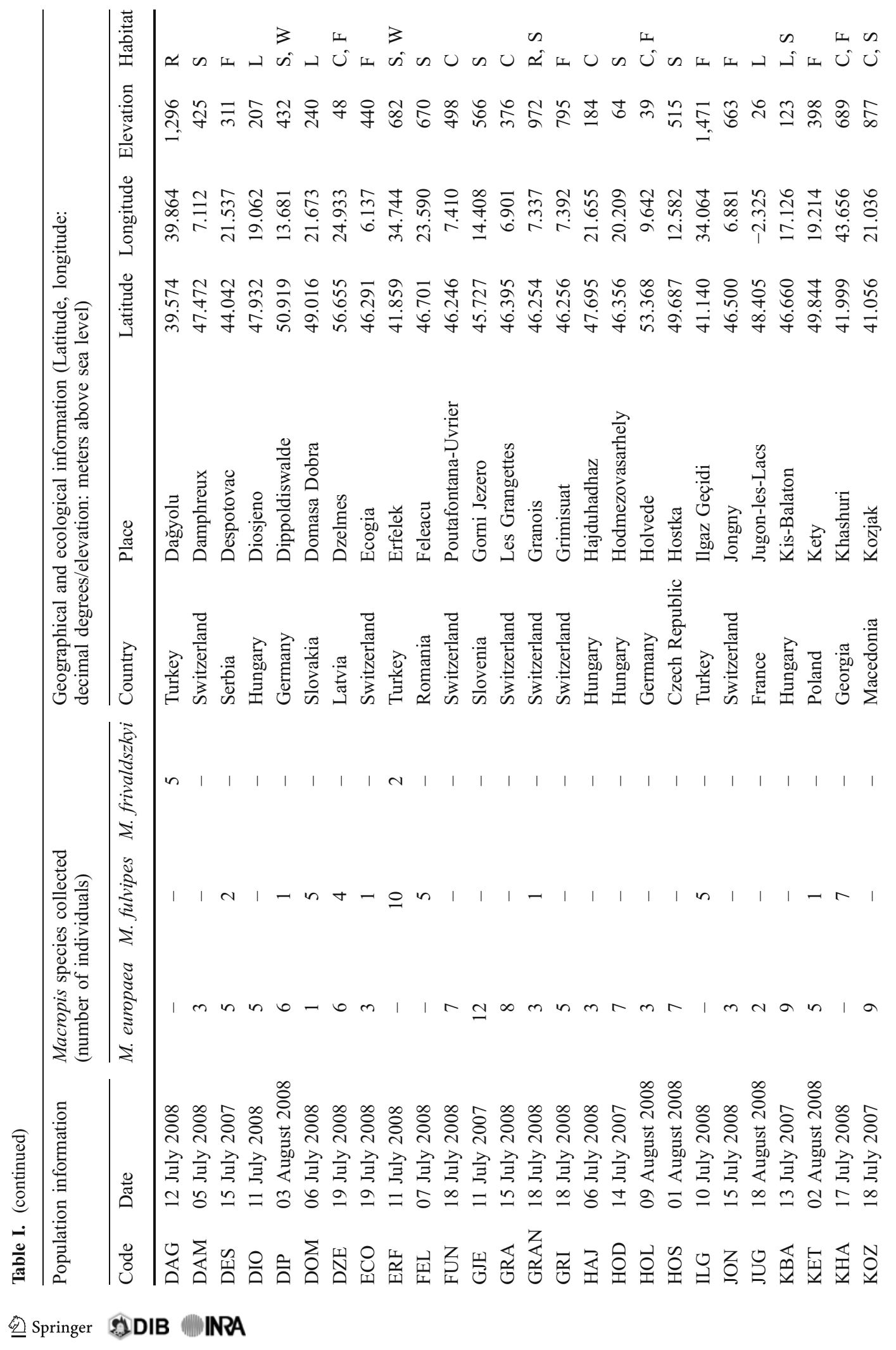




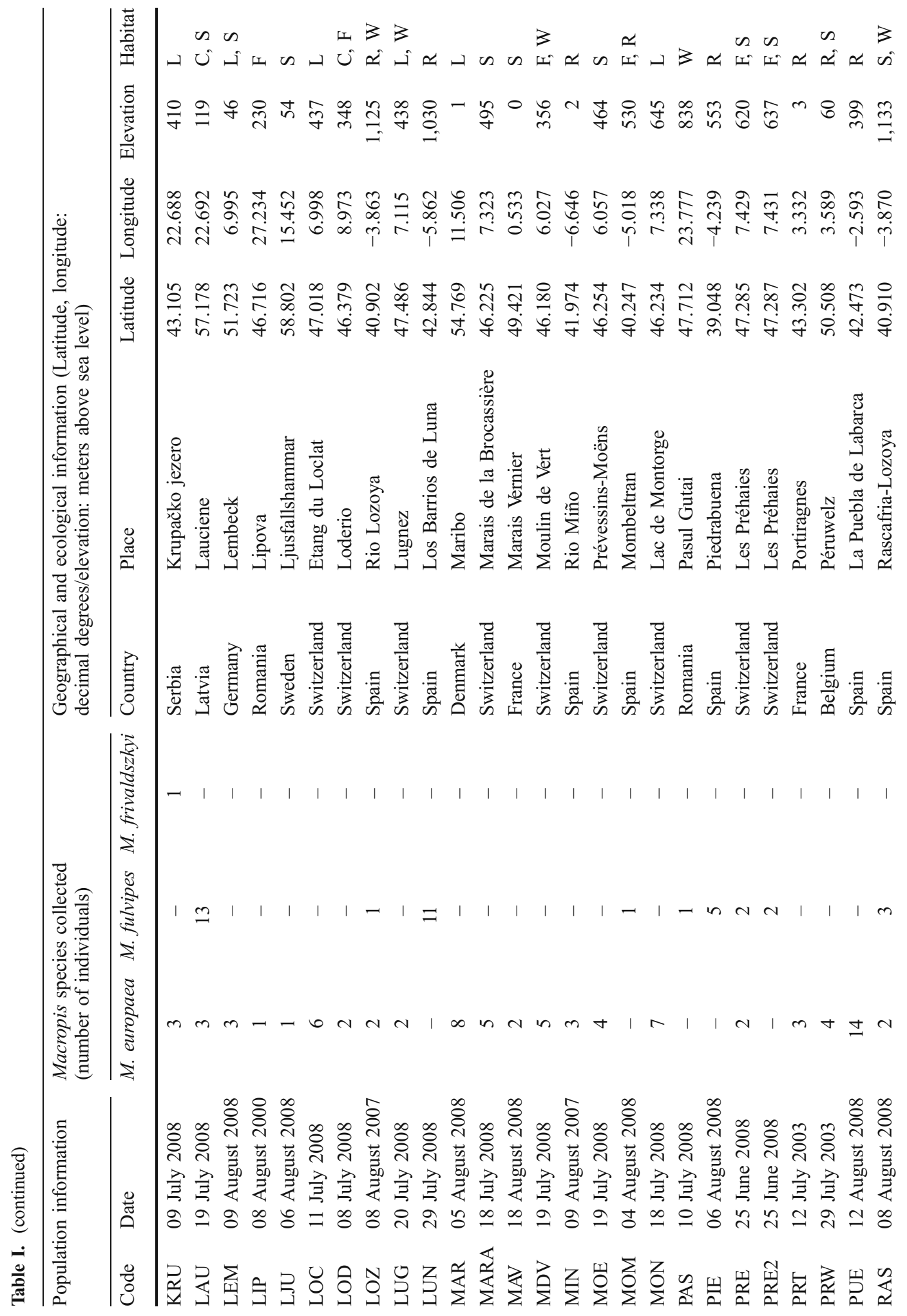




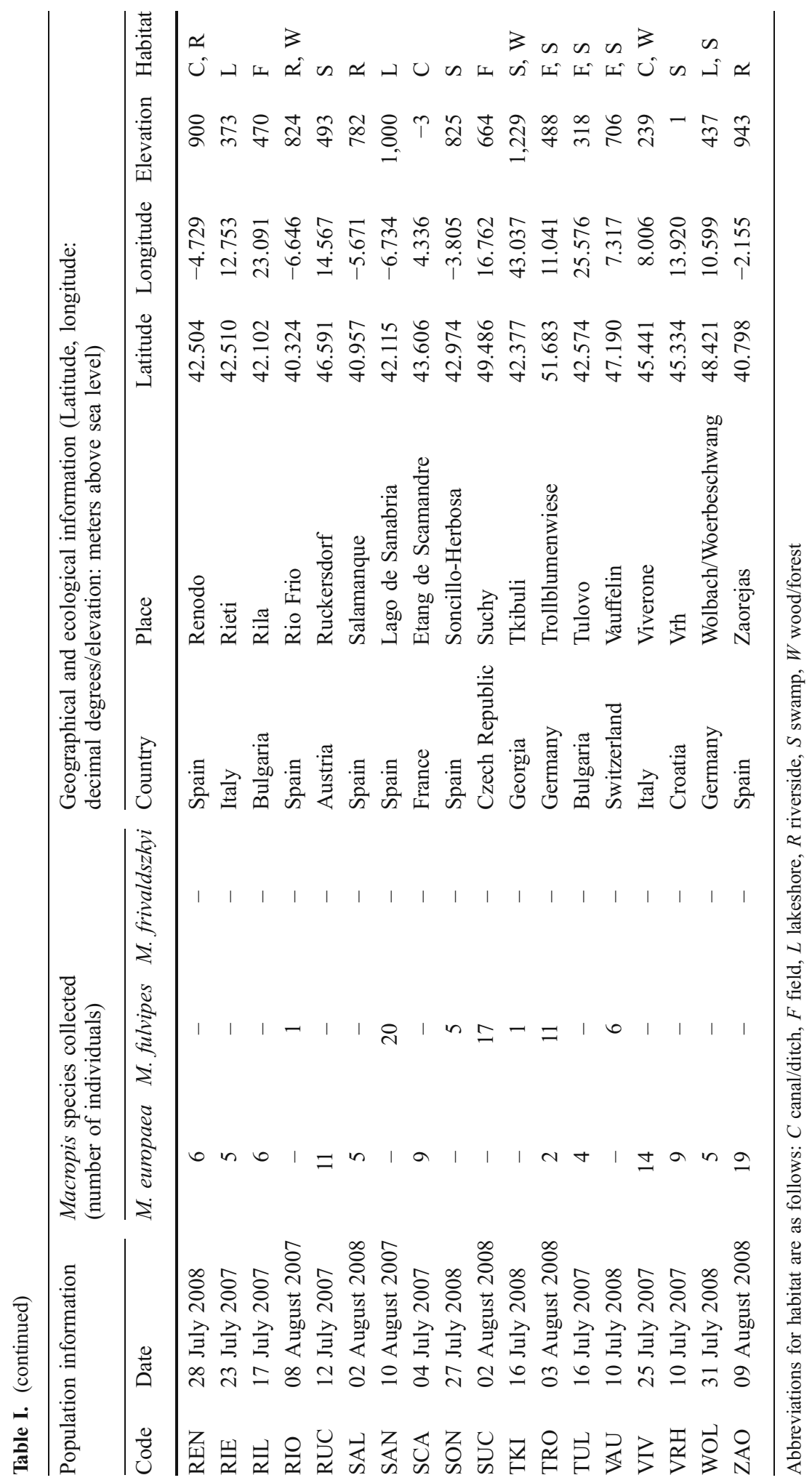


only sampled on L. vulgaris, whereas $M$. fulvipes and $M$. frivaldszkyi were caught on both $L$. vulgaris and L. punctata. Furthermore, two individuals of $M$. fulvipes were observed on $L$. nummularia in one single site in Switzerland (see Supplementary material).

\subsection{Genetic distance between $M$. europaea and M. fulvipes}

Amplification of mitochondrial genes $C O I$, 16s rRNA, and $C y t B$ resulted in alignments of 423, 485, and $150 \mathrm{bp}$, respectively. The largest genetic distance between $M$. europaea and $M$. fulvipes was obtained with $C y t B(0.15 \pm 0.03)$, for which 24 nucleotides were variable (22 parsimony informative). COI was the second most variable gene (distance of $0.09 \pm 0.01$ ), with 35 polymorphic sites (34 parsimony informative). Finally, $16 \mathrm{~s} r R A$ resulted in the smallest distance among species $(0.04 \pm 0.01)$ and showed 22 variable nucleotides (21 parsimony informative). The level of genetic divergence between $M$. frivaldszkyi and the two other bees has not been evaluated yet.

\subsection{Hybridization in Macropis}

In total, 288 individuals (198 M. europaea, 84 M. fulvipes, and six M. frivaldszkyi) were analyzed by AFLP genome fingerprinting in order to detect hybridization between Macropis species. The automatic scoring of the two primer pairs resulted in a total of 471 alleles (out of which 447 were parsimony informative), each individual yielding a minimum of 120 and a maximum of 219 fragments. The PCoA analysis (Figure 2) showed a strong partitioning of species when considering the first three axes (explaining respectively $37.9 \%, 7.9 \%$, and $5.9 \%$ of total variance, i.e., $51.7 \%$ of cumulative variance). Hybridization was rare: only one single individual (a female, sampled in TUL, holding $M$. europaea morphology) showed an intermediate position in the PCoA, typical of hybrids, situated halfway between the scatter plots representative of $M$. europaea and $M$. fulvipes. This hybrid yielded 162 AFLP frag- ments (a number included within the 5-95\% confidence interval of the whole sampling); its intermediate position in the PCoA is thus not an artifact due, for instance, to contamination by two different DNAs, which would have yielded more than twice the minimum number of fragments per individual (i.e., 240 fragments).

\subsection{Mean altitude and latitude comparison between $M$. europaea and M. fulvipes}

Overall, M. europaea was collected at a significantly lower mean altitude $(405 \mathrm{~m}$. a.s. 1.) than was $M$. fulvipes (732 m. a.s.l.) ( $t$ test, $t=$ 4.904, $P<0.001)$. The ANOVA also showed that the mean altitudes of collection were significantly different $(d f=2, P<0.001$; see Figure 3$)$ between allopatric populations of $M$. europaea (360 m. a.s.l), of M. fulvipes $(867 \mathrm{~m}$. a.s.l) and sympatric sites (580 m. a.s.1.). As expected, sampling altitudes significantly decreased as latitude increased, with a strong negative correlation between altitude and latitude for both species (Pearson Product Moment Correlation, $r=-0.54, P<0.0001$ for $M$. europaea and $r=-0.66, P<0.0001$ for $M$. fulvipes). A Mann-Whitney rank sum test showed that there was no significant difference in the sampling latitude between the two species $(P=0.065)$.

\subsection{Ecological niches modeling comparison between M. europaea and M. fulvipes}

The overlapping representation of the respective ecological niches of the two Macropis species on the two first PCA axes based on the Worldclim variables shows that the niche of $M$. fulvipes is slightly larger than that of $M$. europaea (presented in Supplementary material). The Schoener's $D$ metric with its associated statistical tests (Warren et al. 2008) revealed that the ecological niches of each Macropis species were significantly different $(D=0.722, P=0.019)$. Although in relation to the total available environment, the niches remained quite comparable, with the two bee species globally using analogous environmental space. Generally, $M$. fulvipes occupies a slightly larger and more 


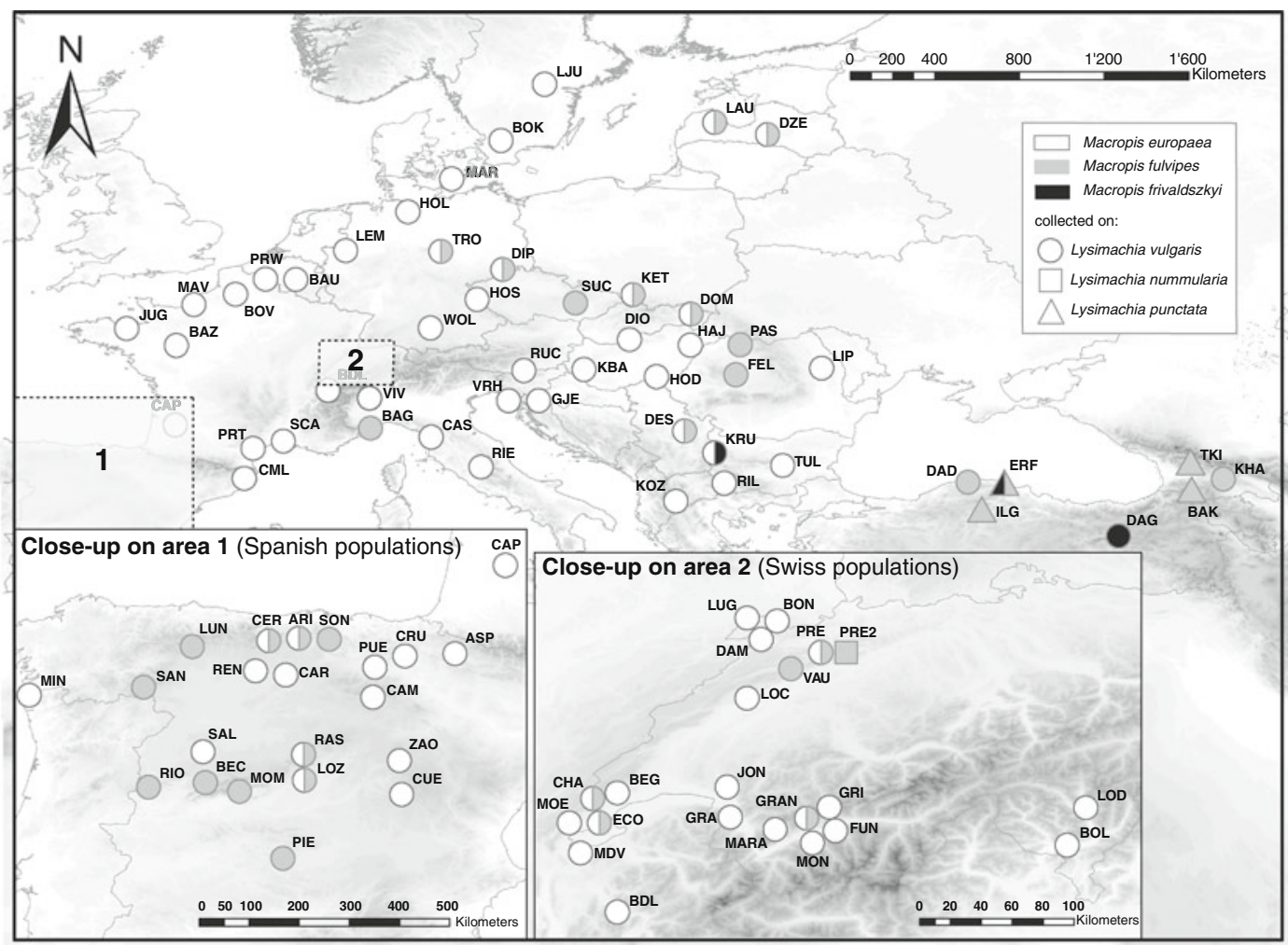

Figure 1. Map showing all Macropis populations sampled. Populations are displayed using different colors representing the three Macropis species, as well as different forms corresponding to the three Lysimachia species on which the bees were collected.

diffuse ecological niche, tolerating colder, more humid but also drier conditions than $M$. europaea. Consequently, differences in the patterns of potential European distribution could be observed for the two species. Figure 4 shows the current modeled distributions of both species. In general, $M$. europaea (Figure 4a) showed a more "temperate oceanic" pattern, with wide optimal areas in central Europe (north from the Alps) as well as in land zones adjacent to Atlantic, Baltic, and North Seas. The species also did not extend much further east than the Carpathians. In contrast, the potential distribution of $M$. fulvipes (Figure 4b) could rather be qualified of "temperate continental", showing a clear Eastern shift of its optimum, especially in the Balkans and the Carpathians, into Russia and around the Black Sea. Globally, suitable areas (in different gray shadings) are more extended in $M$. fulvipes than in $M$. europaea, although optimal environments (in black) are rarer or, in any case, more diffuse. A close-up on the Alpine region confirmed the previous results forecasting $M$. fulvipes to be present at higher elevations (see Figure 4).

\section{DISCUSSION}

\subsection{Important genetic distance as main post-zygotic barrier to hybridization between Macropis species}

Even if hybridization between species might be counter-selected because hybrids tend to fall into adaptive valleys (Coyne and Orr 1998), different cases of hybridization have been 

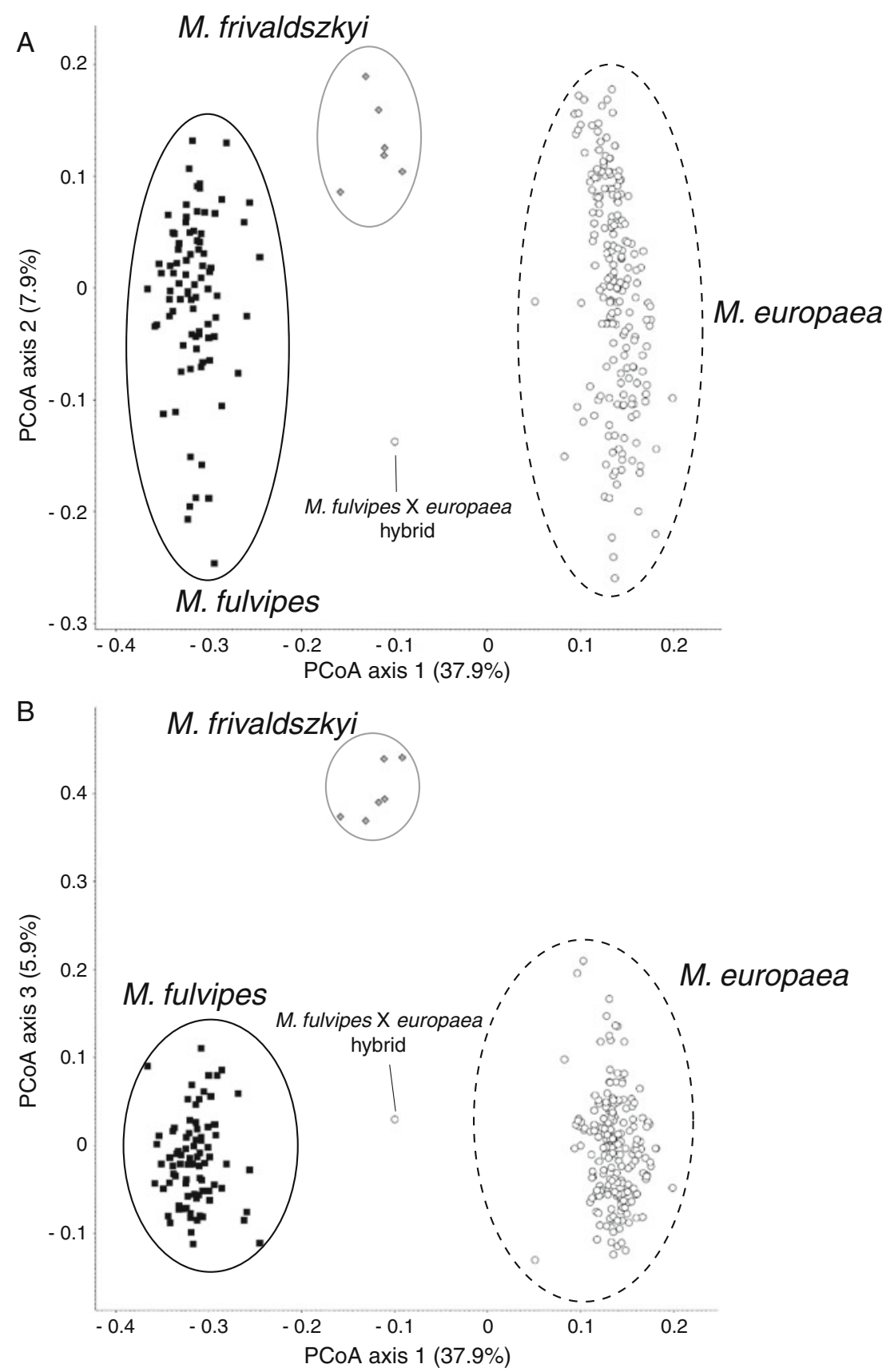

Figure 2. PCoA plot of all Macropis specimens genotyped, showing the potential hybrid detected. Each of the three phenotypic species is displayed on the first two axes (a) as well as on axes 1 and 3 (b).

described in bees (e.g., Ribble 1973; Hall 1990; Rinderer et al. 1991; Nascimento et al. 2000). Based on the assumptions that M. europaea and
M. fulvipes demonstrate (1) similar behaviors and ecologies (e.g., for pollination and reproduction), (2) comparable morphologies, and (3) 


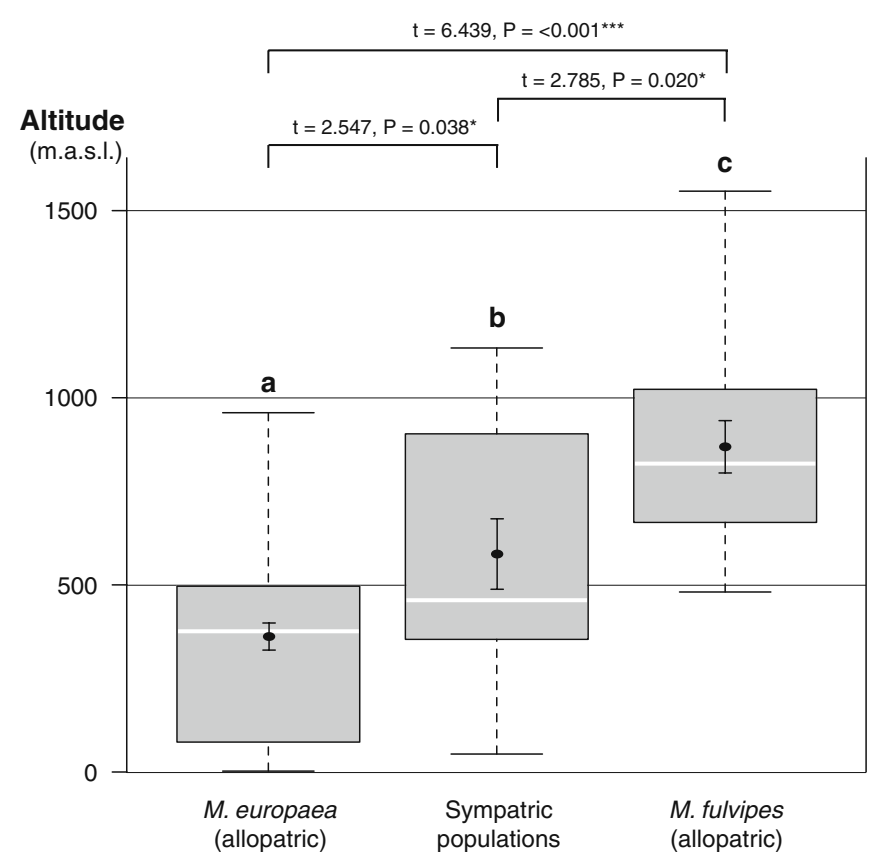

Figure 3. Range of sampling altitudes for the two bee species, either considering allopatric populations (left and right) or sympatric populations (center). For each treatment, the $5-95 \%$ confidence interval of data is shown as a dotted line. Within boxplots are represented the $50 \%$ of data (in gray) and the median (white line). The mean altitude value (with SE) is shown as a black dot over the boxplots. The results of the pairwise comparison (post hoc $t$ test with Bonferroni correction) are shown above for the corresponding means compared.

frequent syntopy (i.e., they are often found in sympatry, collecting oil on the same plant), it could be expected that hybridization occurs between both species. In the current study, hybridization was shown to be rare, since among 291 individuals analyzed only one single confirmed hybrid was identified $(0.3 \%$ of the total sampling).

The scarcity of hybrids can be partly explained by the high level of genetic divergence between these two taxa (e.g., $15 \%$ on $C y t B$ ). Even if $M$. europaea and $M$. fulvipes have been shown to branch together as two sister terminal clades in an ongoing phylogenetic study on Mellittidae including six Macropis taxa (Michez, personal communication), their genetic divergence is at the upper limit of values observed for sister species within the genus (Sheffield et al. 2009). Such a high genetic distance indicates that these two species have diverged long before the Pleistocene, probably in the Pliocene or even the Miocene. As a consequence, post-zygotic reproductive incompatibility between these species is probably well established.

\subsection{Behavioral and ecological pre-zygotic barriers as local-scale impediments to hybrid formation}

Although the high level of genetic divergence might explain the rarity of natural hybrids, the differences in the respective phenologies of $M$. europaea and M. fulvipes could still decrease their co-occurrence locally. Phenological studies available for Macropis report a slight offset (from 10 to 20 days) in the activity of the bee species (Westrich 1990; Pekkarinen et al. 2003; Celary 2004). Such an offset in the timing activity could thus represent a pre-zygotic barrier to interspecific reproduction, presumably with the larger the offset, the stronger the barrier. Stronger barriers to hybridization might rather affect 

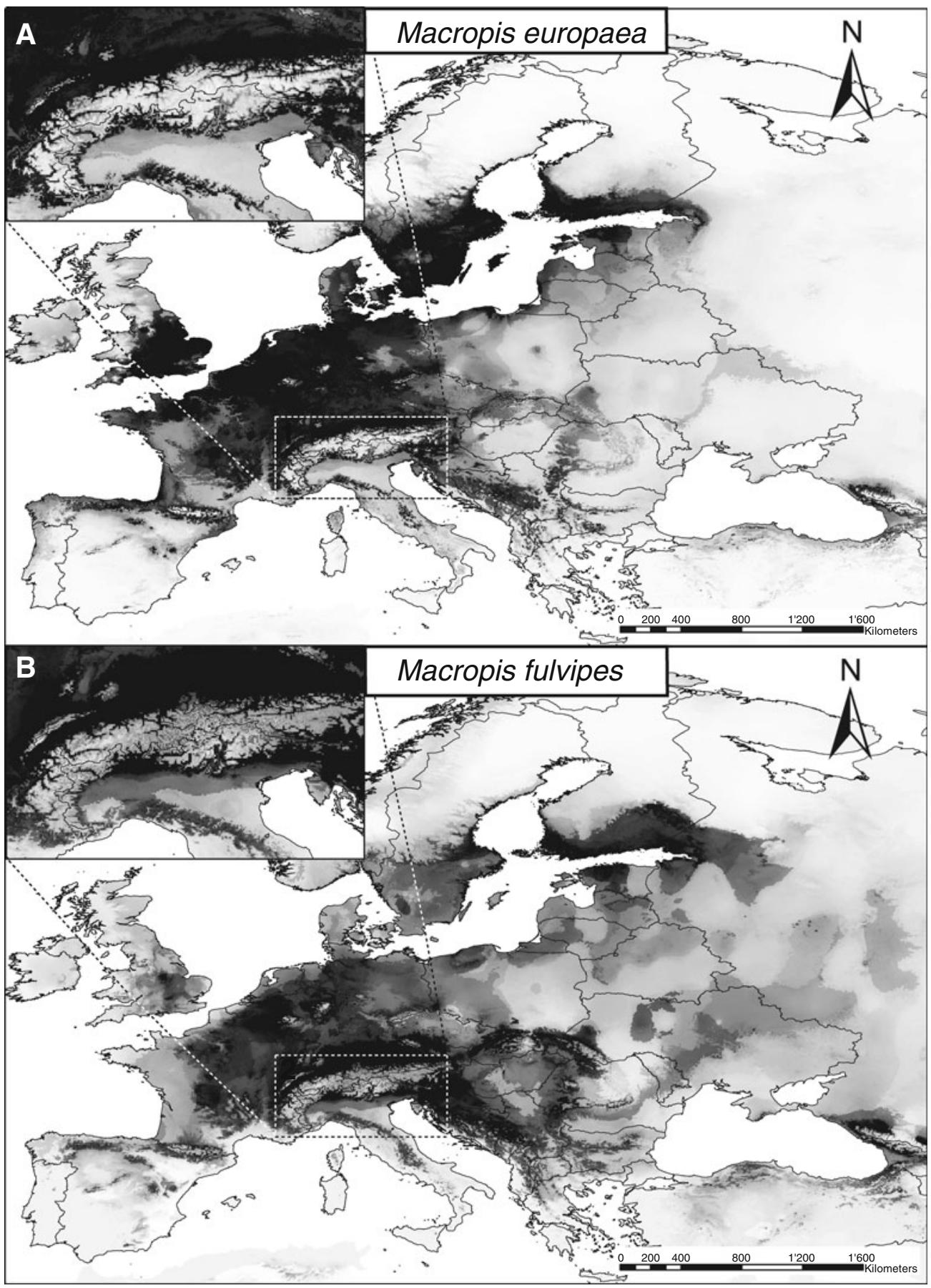

Figure 4. Modeling of the current potential European distributions of M. europaea (a) and M. fulvipes (b); the darker is an area, the higher is the probability that the ecological conditions in this area are optimal for the species. A close-up on the Alpine region is provided for each species, in order to compare the potential distributions in altitude. 
southern populations, where the seasonal period of activity would start sooner and finish later, with a larger offset in the bees phenologies (although this is speculative since all available phenological studies were performed in northern European countries: Germany, Finland, and Poland, respectively). However, the same studies have shown that the two bee species co-exist for at least 1 month, especially during 1 or 2 weeks of shared intense activity. This period would be long enough to provide opportunities for the two species to meet and mate (notably between late-emerging $M$. fulvipes males and early-emerging $M$. europaea females). Because of the rare occurrence of natural hybridization, one might expect that the offset in respective phenologies locally reinforces the pre-zygotic reproductive barrier between the two species, although this feature is probably not a key factor in preventing hybridization.

Our large-scale study also revealed ecological trends that challenge previously reported observations on Macropis, notably regarding floral preferences or habitat associations. The presumed preference of $M$. fulvipes for $L$. nummularia (previously reported by Westrich 1990 or Pekkarinen et al. 2003) must be refuted. Macropis fulvipes certainly sometimes visits this plant (see Supplementary material), but it is principally dependant either on $L$. vulgaris in most of Europe or on L. punctata in southeastern Europe, Turkey and Caucasus. Previous conclusions concerning habitat associations should also be tempered. Some authors mentioned that M. europaea was mostly associated with open habitats (flood plains, wetlands) and M. fulvipes with forests (Westrich 1990). Even though such association might occur at a local scale (e.g., in Baden-Württemberg; Westrich 1990), evidence at a wider scale was lacking until the present study. In our results (see Table I), we observed that most sampled populations are located in open habitats such as swamps, wet fields, along rivers or lakeshores, and that both $M$. fulvipes and $M$. europaea are only rarely found in forests (probably because L. vulgaris and L. punctata, when growing in closed habitats, are generally less developed and harbor sparser inflorescen- ces compared to plants from open locations). Hence, we cannot conclude that $M$. fulvipes is more associated with woody areas than is $M$. europaea at the European scale. Small-scale partitioning factors, such as floral or habitat preferences, might then represent additional factors that, in association with the phenological offset described above, could locally reduce the probability of co-occurrence and reinforce prezygotic barriers to hybridization between $M$. europaea and M. fulvipes. However, when considering the whole distribution ranges of these bees, large-scale partitioning factors such as climatic preferences (see below) are more likely to play essential barriers to hybridization and competition by limiting sympatry between these two bee species.

\subsection{New insights on the climatic preferences and spatial distributions of $M$. europaea and $M$. fulvipes}

In our study, at least three observations confirm the shift in ecological niches of the two species: (1) despite model predictions forecasting rather similar optimal areas for the two species in a large part of central Europe (Figure 4), we have identified only scarce sympatric populations (15 sites on our whole European sampling, see Figure 1); (2) occurrences in our sampling were spatially more continuous for $M$. europaea than for $M$. fulvipes, the latter being most frequent in mountainous areas; and (3) niches were significantly different as attested by the significant test for the Schoener's metric (i.e., the one of $M$. fulvipes being slightly larger than that of $M$. europaea). When confronting (1) and (2) to the paradigm of ecological valence sensu Dajoz (1978), we can consider M. fulvipes as an euryoecic species tolerating a larger ecological range (e.g., potential habitats, flower preference) than $M$. europaea, which is more stenoecic. Indeed, $M$. fulvipes is not only present in more climatically harsh regions (e.g., the Alps; see Figure 4), but it is also able to collect oil from other Lysimachia species (Figure 1, also see the L. nummularia pollination study in the 
Supplementary material), even if L. vulgaris remains its more frequent oil-providing plant species in Europe. In contrast, M. europaea shows higher probabilities of occurrence in more temperate climatic zones and there is no convincing evidence yet of $M$. europaea feeding on other oil-providing plants (data compiled until here are anecdotal). Consequently, $M$. europaea is also expected to be more competitive than $M$. fulvipes when both species are found in sympatry on L. vulgaris. The less competitive $M$. fulvipes would then replace $M$. europaea in habitats with harsher conditions, as shown by the significantly higher mean altitude where M. fulvipes was collected (see Figure 3). Sympatric sites are therefore not as frequent as expected by the ecological niche models because they could only be located in transitional areas, where M. europaea reaches its ecological limits and becomes less competitive. Indeed, the 15 sympatric sites stand at a mean altitude of 580 m. a.s.1., the almost exactly halfway between mean altitudes of each bee species when found in allopatry. In the sympatric sites where the respective climatic preferences of $M$. europaea and M. fulvipes overlap, their considerable genetic distance still acts as a strong postzygotic barrier, keeping hybridization events as rare as found in the current study.

\section{CONCLUSION}

Due to the probable combination of both genetic and ecological factors impeding the formation of hybrids between Macropis species, the frequency and localization of such events remain difficult to forecast. A more intensive screening of the sympatric populations, especially from the Balkanic range (where populations enclosing all three European Macropis species might exist, and with a single hybrid detected from the Bulgarian population TUL) could reveal further hybridization events, which could also involve $M$. frivaldszkyi as another potential parent for hybrid specimens. Despite the fact that the two bees share similar ecological and morphological features, the current study suggests that European Macropis species efficiently avoid hybridization, as was evidenced by (1) a high level of genetic divergence and (2) differences in their climatic niches, locally associated with more subtle factors such as phenological offset and differences in floral choice or habitat preferences.

\section{ACKNOWLEDGMENTS}

The authors want to warmly thank all people that have preciously helped during fieldwork sampling: R. Arnoux, P. Bassin, A. Espíndola, A. Favre, I. Hiltpold, D. Kharazishvili, and B. Prudat. A special thank to A. Sarr for support with AFLP analysis and to B. Schatz for collaboration with the chemical analyses. We especially want to thank D. Michez for providing additional samples for DNA analysis, geographical databases for niches modeling, and for providing helpful comments. We are grateful to F. Amiet and J.-P. Haenni for the accurate determination of pollinators. We also thank the Centre du Réseau Suisse de Floristique (CRSF) for providing geographic coordinates of Swiss Lysimachia populations. This research was supported by the Swiss National Science Foundation (grant no. 3100A0-116778). The fieldwork was additionally granted by the travel grants commission of the Swiss Academy of Sciences (SCNAT) and by the M. Wütrich and A. Mathey-Dupraz Foundation (University of Neuchâtel).

Chevauchement des niches écologiques chez 2 espèces sœurs: comment les abeilles récolteuses d'huile Macropis europaea et M. fulvipes (Hymenoptera : Melittidae) évitent-elles l'hybridation et la compétition?

Macropis / mutualisme / Lysimachia / niche écologique / hybridation

Die Überlappung ökologischer Nischen bei Geschwisterarten: Wie vermeiden die ölsammelnden Bienen Macropis europaea und M. fulvipes (Hymenoptera: Melittidae) die Hybridbildung und innerartliche Konkurrenz?

Macropis / Mutualismus / Lysimachia / ökologische Nische / Hybridbildung 


\section{REFERENCES}

Belshaw, R., Quicke, D.L.J. (1997) A molecular phylogeny of the Aphidiinae (Hymenoptera: Braconidae). Mol. Phylogenet. Evol. 73, 281-293

Bouxin, G. (2005) Ginkgo, a multivariate analysis package. J. Veg. Sci. 163, 355-359

Broenimann, O., Fitzpatrick, M.C., Pearman, P.B., Petitpierre, B., Pellissier, L., Yoccoz, N.G., Thuiller, W., Fortin, M.J., Randin, C.R., Zimmermann, N.E., Graham, C.H., Guisan, A. (in press) Measuring ecological niche overlap from occurrence and spatial environmental data. Global Ecol. Biogeogr.

Bronstein, J.L., Alarcón, R., Geber, M. (2006) The evolution of plant-insect mutualisms. New Phytol. 1723, 412-428

Cane, J.H., Eickwort, G.C., Wesley, F.R., Spielholz, J. (1983) Foraging, grooming and mate-seeking behaviors of Macropis nuda (Hymenoptera, Melittidae) and use of Lysimachia ciliata (Primulaceae) oils in larval provisions and cell linings. Am. Midl. Nat. 1102, 257-264

Celary, W. (2004) A comparative study on the biology of Macropis fulvipes (Fabricius, 1804) and Macropis europaea Warncke, 1973 (Hymenoptera: Apoidea: Melittidae). Folia Biol.-Krakow 521-2, 81-85

Cook, J.M., Rasplus, J.Y. (2003) Mutualists with attitude: coevolving fig wasps and figs, Trends Ecol. Evol. 185, 241-248

Coyne, J.A., Orr, H.A. (1998) The evolutionary genetics of speciation. Philos. Trans. R. Soc. Lond. Ser. BBiol. Sci. 353, 287-305

Dajoz, R. (1978) Précis d'écologie. Dunod, Paris

Hall, H.G. (1990) Parental analysis of introgressive hybridization between African and European honeybees using nuclear-DNA RFLPs. Genetics 1253, 611-621

Hall, T.A. (1999) BioEdit: a user-friendly biological sequence alignment editor and analysis program for Windows 95/98/NT. Nucleic Acids Symp. 41, 95-98

Hao, G., Yuan, Y.M., Hu, C.M., Ge, X.J., Zhao, N.X. (2004) Molecular phylogeny of Lysimachia (Myrsinaceae) based on chloroplast trnL-F and nuclear ribosomal ITS sequences. Mol. Phylogenet. Evol. 311, 323-339

Hijmans, R.J., Cameron, S.E., Parra, J.L., Jones, P.G., Jarvis, A. (2005) Very high resolution interpolated climate surfaces for global land areas. Int. J. Climatol. 2515, 1965-1978

Jaccard, P. (1908) Nouvelles recherches sur la distribution florale. Bull. Soc. Vaud. Sci. Nat. 22, 223-270

Kumar, S., Nei, M., Dudley, J., Tamura, K. (2008) MEGA: A biologist-centric software for evolutionary analysis of DNA and protein sequences. Brief. Bioinform. 94, 299-306

Machado, C.A., Robbins, N., Gilbert, M.T.P., Herre, E.A. (2005) Critical review of host specificity and its coevolutionary implications in the fig/fig-wasp mutualism. Proc. Natl. Acad. Sci. U. S. A. 102, 6558-6565

Marmion, M., Parviainen, M., Luoto, M., Heikkinen, R. K., Thuiller, W. (2009) Evaluation of consensus methods in predictive species distribution modelling. Divers. Distrib. 151, 59-69

Michener, C.D. (2000) The bees of the world. The Johns Hopkinds University Press, Baltimore

Michez D., 2002. Monographie systématique, biogéographique et écologique des Melittidae (Hymenoptera, Apoidea) de l'Ancien Monde - Premières données et premières analyses. Faculté Universitaire des Sciences Agronomiques de Gembloux, Gembloux.

Michez, D., Nel, A., Menier, J.J., Rasmont, P. (2007) The oldest fossil of a melittid bee (Hymenoptera: Apiformes) from the early Eocene of Oise (France). Zool. J. Linn. Soc. 1504, 701-709

Michez, D., Patiny, S. (2005) World revision of the oilcollecting bee genus Macropis Panzer 1809 (Hymenoptera: Apoidea: Melittidae) with a description of a new species from Laos. Ann. Soc. Entomol. Fr. 411, $15-28$

Nascimento, V.A., Matusita, S.H., Kerr, W.E. (2000) Evidence of hybridization between two species of Melipona bees. Genet. Mol. Biol. 231, 79-81

Pekkarinen, A., Berg, O., Calabuig, I., Janzon, L.A., Luig, J. (2003) Distribution and co-existence of the Macropis species and their cleptoparasite Epeoloides coecutiens (Fabr.) in NW Europe (Hymenoptera: Apoidea, Melittidae and Apidae). Entomol. Fenn. 141, 53-59

Pellmyr, O. (2003) Yuccas, yucca moths, and coevolution: A review. Ann. Mo. Bot. Gard. 901, 35-55

Rasmussen, C., Olesen, J.M. (2000) Oil flowers and oilcollecting bees. Scandinavian Association for Pollination Ecology honours Knut Fegri 39, 23-31

Renner, S.S., Schaefer, H. (2010) The evolution and loss of oil-offering flowers: new insights from dated phylogenies for angiosperms and bees. Philos. Trans. R. Soc. B-Biol. Sci. 365(1539), 423-435

Ribble, D.W. (1973) Hybridization between three species of andrenid bees. Ann. Entomol. Soc. Am. 666, 1281-1286

Rinderer, T.E., Stelzer, J.A., Oldroyd, B.P., Buco, S.M., Rubink, W.L. (1991) Hybridization between European and Africanized honey-bees in the neotropical Yucatan peninsula. Science 253, 309-311

Sheffield, C.S., Hebert, P.D.N., Kevan, P.G., Packer, L. (2009) DNA barcoding a regional bee (Hymenoptera: Apoidea) fauna and its potential for ecological studies. Mol. Ecol. Resour. 9, 196-207

Simon, C., Frati, F., Beckenbach, A., Crespi, B., Liu, H., Flook, P. (1994) Evolution, weighting, and phylogenetic utility of mitochondrial gene-sequences and a compilation of conserved polymerase chain-reaction primers. Ann. Entomol. Soc. Am. 876, 651-701 
Simpson, B.B., Neff, J.L., Seigler, D.S. (1983) Floral biology and floral rewards of Lysimachia (Primulaceae). Am. Midl. Nat. 1102, 249-256

Thompson, J.D., Gibson, T.J., Plewniak, F., Jeanmougin, F., Higgins, D.G. (1997) The clustalX windows interface: flexible strategies for multiple sequence alignment aided by quality analysis tools. Nucleic Acids Res. 24, 4876-4882

Thuiller, W., Lafourcade, B., Engler, R., Araújo, M.B. (2009) BIOMOD - a platform for ensemble forecasting of species distributions. Ecography 323, 369-373

Vogel, S. (1976) Lysimachia: Ölblumen des Holartiks. Naturwissenschaften 63, 44-45

Vogel S. (1986) Ölblumen and Ölsammelnde Bienen: Zweite Folge Lysimachia und Macropis, in: Verl. F.
S. (Ed.), Akademie der Wissenschaftenund der Literatur Mainz, Stuttgart, Germany.

Vogel, S. (1988) The oil-bee oil-flower relationships: parallelism and other aspects of their evolution in space and time. Z. Zool. Syst. Evol. 265, 341362

Vos, P., Hogers, R., Bleeker, M., Reijans, M., van de Lee, T., Hornes, M., Frijters, A., Pot, J., Peleman, J., Kuiper, M., Zabeau, M. (1995) AFLP- a new technique for DNAfingerprinting. Nucleic Acids Res. 2321, 4407-4414

Warren, D.L., Glor, R.E., Turelli, M. (2008) Environmental niche equivalency versus conservatism: quantitative approaches to niche evolution. Evolution 6211, 2868-2883

Westrich P. (1990) Die Wildbienen Baden-Württembergs, Ulmer Verlag, Stuttgart. 